Federal Reserve Bank of Minneapolis

\title{
Quarterly Review
}

Modern Business Cycle Analysis: A Guide to the Prescott-Summers Debate (p. 3)

Rodolfo E. Manuelli

Theory Ahead of Business Cycle Measurement (p. 9)

Edward C. Prescott

Some Skeptical Observations on Real Business Cycle Theory (p. 23)

Lawrence H. Summers

Response to a Skeptic (p. 28)

Edward C. Prescott 
Federal Reserve Bank of Minneapolis

\section{Quarterly Review}

Vol. 10, No. 4 ISSN 0271-5287

This publication primarily presents economic research aimed at improving policymaking by the Federal Reserve System and other governmental authorities.

Produced in the Research Department. Edited by Preston J. Miller and Kathleen S. Rolfe. Graphic design by Phil Swenson and typesetting by Barb Cahlander and Terri Desormey, Graphic Services Department.

Address questions to the Research Department, Federal Reserve Bank, Minneapolis, Minnesota 55480 (telephone 612-340-2341).

Articles may be reprinted if the source is credited and the Research Department is provided with copies of reprints.

The views expressed herein are those of the authors and not necessarily those of the Federal Reserve Bank of Minneapolis or the Federal Reserve System. 


\title{
Some Skeptical Observations on Real Business Cycle Theory*
}

\author{
Lawrence H. Summers \\ Professor of Economics \\ Harvard University \\ and Research Associate \\ National Bureau of Economic Research
}

The increasing ascendancy of real business cycle theories of various stripes, with their common view that the economy is best modeled as a floating Walrasian equilibrium, buffeted by productivity shocks, is indicative of the depths of the divisions separating academic macroeconomists. These theories deny propositions thought self-evident by many academic macroeconomists and all of those involved in forecasting and controlling the economy on a day-to-day basis. They assert that monetary policies have no effect on real activity, that fiscal policies influence the economy only through their incentive effects, and that economic fluctuations are caused entirely by supply rather than demand shocks.

If these theories are correct, they imply that the macroeconomics developed in the wake of the Keynesian Revolution is well confined to the ashbin of history. And they suggest that most of the work of contemporary macroeconomists is worth little more than that of those pursuing astrological science. According to the views espoused by enthusiastic proponents of real business cycle theories, astrology and Keynesian economics are in many ways similar: both lack scientific support, both are premised on the relevance of variables that are in fact irrelevant, both are built on a superstructure of nonoperational and ill-defined concepts, and both are harmless only when they are ineffectual.

The appearance of Ed Prescott's stimulating paper, "Theory Ahead of Business Cycle Measurement," affords an opportunity to assess the current state of real business cycle theory and to consider its prospects as a foundation for macroeconomic analysis. Prescott's paper is brilliant in highlighting the appeal of real business cycle theories and making clear the assumptions they require. But he does not make much effort at caution in judging the potential of the real business cycle paradigm. He writes that "if the economy did not display the business cycle phenomena, there would be a puzzle," characterizes without qualification economic fluctuations as "optimal responses to uncertainty in the rate of technological change," and offers the policy advice that "costly efforts at stabilization are likely to be counterproductive."

Prescott's interpretation of his title is revealing of his commitment to his theory. He does not interpret the phrase theory ahead of measurement to mean that we lack the data or measurements necessary to test his theory. Rather, he means that measurement techniques have not yet progressed to the point where they fully corroborate his theory. Thus, Prescott speaks of the key deviation of observation from theory as follows: "An important part of this deviation could very well disappear if the economic variables were measured more in conformity with theory. That is why I argue that theory is now ahead of business cycle measurement. ..."

The claims of real business cycle theorists deserve

*An earlier version of these remarks was presented at the July 25,1986 , meeting of the National Bureau of Economic Research Economic Fluctuations Group. 
serious assessment, especially given their source and their increasing influence within the economics profession. Let me follow Prescott in being blunt. My view is that real business cycle models of the type urged on us by Prescott have nothing to do with the business cycle phenomena observed in the United States or other capitalist economies. Nothing in Prescott's papers or those he references is convincing evidence to the contrary.

Before turning to the argument Prescott presents, let me offer one lesson from the history of science. Extremely bad theories can predict remarkably well. Ptolemaic astronomy guided ships and scheduled harvests for two centuries. It provided extremely accurate predictions regarding a host of celestial phenomena. And to those who developed it, the idea that the earth was at the center seemed an absolutely natural starting place for a theory. So, too, Lamarckian biology, with its emphasis on the inheritance of acquired characteristics, successfully predicted much of what was observed in studies of animals and plants. Many theories can approximately mimic any given set of facts; that one theory can does not mean that it is even close to right.

Prescott's argument takes the form of the construction of an artificial economy which mimics many of the properties of actual economies. The close coincidence of his model economy and the actual economy leads him to conclude that the model economy is a reasonable if abstract representation of the actual economy. This claim is bolstered by the argument that the model economy is not constructed to fit cyclical facts but is parameterized on the basis of microeconomic information and the economy's long-run properties. Prescott's argument is unpersuasive at four levels.

\section{Are the Parameters Right?}

First, Prescott's claim to have parameterized the model on the basis of well-established microeconomic and long-run information is not sustainable. As one example, consider a parameter which Prescott identifies as being important in determining the properties of the model, the share of household time devoted to market activities. He claims that is one-third. Data on its average value over the last century indicate, as Martin Eichenbaum, Lars Hansen, and Kenneth Singleton (1986) have noted, an average value of one-sixth over the past 30 years. This seems right - a little more than half the adult population works, and those who work work about a quarter of the time. I am unable to find evidence supporting Prescott's one-third figure in the cited book by Gilbert Ghez and Gary Becker (1975). To take another example, Prescott takes the average real interest rate to be 4 percent. Over the 30 -year period he studies, it in fact averaged only about 1 percent. This list of model parameters chosen somewhat arbitrarily could be easily extended.

A more fundamental problem lies in Prescott's assumption about the intertemporal elasticity of substitution in labor supply. He cites no direct microeconomic evidence on this parameter, which is central to his model of cyclical fluctuations. Nor does he refer to any aggregate evidence on it. Rather, he relies on a rather selective reading of the evidence on the intertemporal elasticity of substitution in consumption in evaluating the labor supply elasticity. My own reading is that essentially all the available evidence suggests only a minimal response of labor to transitory wage changes. Many studies (including Altonji 1982; Mankiw, Rotemberg, and Summers 1985; and Eichenbaum, Hansen, and Singleton 1986) suggest that the intertemporal substitution model cannot account at either the micro or the macro level for fluctuations in labor supply.

Prescott is fond of parameterizing models based on long-run information. Japan has for 30 years enjoyed real wage growth at a rate four times the U.S. rate, close to 8 percent. His utility function would predict that such rapid real wage growth would lead to a much lower level of labor supply by the representative consumer. I am not aware that this pattern is observed in the data. Nor am I aware of data suggesting that age/hours profiles are steeper in professions like medicine or law, where salaries rise rapidly with age.

Prescott's growth model is not an inconceivable representation of reality. But to claim that its parameters are securely tied down by growth and micro observations seems to me a gross overstatement. The image of a big loose tent flapping in the wind comes to mind.

\section{Where Are the Shocks?}

My second fundamental objection to Prescott's model is the absence of any independent corroborating evidence for the existence of what he calls technological shocks. This point is obviously crucial since Prescott treats technological shocks as the only driving force behind cyclical fluctuations. Prescott interprets all movements in measured total factor productivity as being the result of technology shocks or to a small extent measurement error. He provides no discussion of the source or nature of these shocks, nor does he cite any microeconomic evidence for their importance. I suspect that the vast majority of what Prescott labels technology shocks are in fact the observable concomi- 
tants of labor hoarding and other behavior which Prescott does not allow in his model.

Two observations support this judgment. First, it's hard to find direct evidence of the existence of large technological shocks. Consider the oil shocks, certainly the most widely noted and commented on shocks of the postwar period. How much might they have been expected to reduce total factor productivity? In one of the most careful studies of this issue, Ernst Berndt $(1980$, p. 85$)$ concludes that "energy price or quantity variations since 1973 do not appear to have had a significant direct role in the slowdown of aggregate labor productivity in U.S. manufacturing, 1973-77." This is not to deny that energy shocks have important effects. But they have not accounted for large movements in measured total factor productivity.

Prescott assumes that technological changes are irregular, but is unable to suggest any specific technological shocks which presage the downturns that have actually taken place. A reasonable challenge to his model is to ask how it accounts for the 1982 recession, the most serious downturn of the postwar period. More generally, it seems to me that the finding that measured productivity frequently declines is difficult to account for technologically. What are the sources of technical regress? Between 1973 and 1977, for example, both mining and construction displayed negative rates of productivity growth. For smaller sectors of the economy, negative productivity growth is commonly observed.

A second observation casting doubt on Prescott's assumed driving force is that while technological shocks leading to changes in total factor productivity are hard to find, other explanations are easy to support. Jon Fay and James Medoff (1985) surveyed some 170 firms on their response to downturns in the demand for their output. The questions asked were phrased to make clear that it was exogenous downturns in their output that were being inquired about. Fay and Medoff (1985, p. 653) summarize their results by stating that "the evidence indicates that a sizeable portion of the swings in productivity over the business cycle is, in fact, the result of firms' decisions to hold labor in excess of regular production requirements and to hoard labor." According to their data, the typical plant in the U.S. manufacturing sector paid for 8 percent more bluecollar hours than were needed for regular production work during the trough quarter of its most recent downturn. After taking account of the amount of other worthwhile work that was completed by blue-collar employees during the trough quarter, 4 percent of the blue-collar hours paid for were hoarded. Similar conclusions have been reached in every other examination of microeconomic data on productivity that I am aware of.

In Prescott's model, the central driving force behind cyclical fluctuations is technological shocks. The propagation mechanism is intertemporal substitution in employment. As I have argued so far, there is no independent evidence from any source for either of these phenomena.

\section{What About Prices? ...}

My third fundamental objection to Prescott's argument is that he does price-free economic analysis. Imagine an analyst confronting the market for ketchup. Suppose she or he decided to ignore data on the price of ketchup. This would considerably increase the analyst's freedom in accounting for fluctuations in the quantity of ketchup purchased. Indeed, without looking at the price of ketchup, it would be impossible to distinguish supply shocks from demand shocks. It is difficult to believe that any explanation of fluctuations in ketchup sales that did not confront price data would be taken seriously, at least by hard-headed economists.

Yet Prescott offers us an exercise in price-free economics. While real wages, interest rates, and returns to capital are central variables in his model, he never looks at any data on them except for his misconstrual of the average real interest rate over the postwar period. Others have confronted models like Prescott's to data on prices with what I think can fairly be labeled dismal results. There is simply no evidence to support any of the price effects predicted by the model. Prescott's work does not resolve-or even mention-the empirical reality emphasized by Robert Barro and Robert King (1982) that consumption and leisure move in opposite directions over the business cycle with no apparent procyclicality of real wages. It is finessed by ignoring wage data. Prescott's own work with Rajnish Mehra (1985) indicates that the asset pricing implications of models like the one he considers here are decisively rejected by nearly 100 years of historical experience. I simply do not understand how an economic model can be said to have been tested without price data.

I believe that the preceding arguments demonstrate that real business cycle models of the type surveyed by Prescott do not provide a convincing account of cyclical fluctuations. Even if this strong proposition is not accepted, they suggest that there is room for factors other than productivity shocks as causal elements in cyclical fluctuations. 


\section{... And Exchange Failures?}

A fourth fundamental objection to Prescott's work is that it ignores the fact that partial breakdowns in the exchange mechanism are almost surely dominant factors in cyclical fluctuations. Consider two examples. Between 1929 and 1933, the gross national product in the United States declined 50 percent, as employment fell sharply. In Europe today, employment has not risen since 1970 and unemployment has risen more than fivefold in many countries. I submit that it defies credulity to account for movements on this scale by pointing to intertemporal substitution and productivity shocks. All the more given that total factor productivity has increased more than twice as rapidly in Europe as in the United States.

If some other force is responsible for the largest fluctuations that we observe, it seems quixotic methodologically to assume that it plays no role at all in other smaller fluctuations. Whatever mechanisms may have had something to do with the depression of the 1930s in the United States or the depression today in Europe presumably have at least some role in recent American cyclical fluctuations.

What are those mechanisms? We do not yet know. But it seems clear that a central aspect of depressions, and probably economic fluctuations more generally, is a breakdown of the exchange mechanism. Read any account of life during the Great Depression in the United States. Firms had output they wanted to sell. Workers wanted to exchange their labor for it. But the exchanges did not take place. To say the situation was constrained Pareto optimal given the technological decline that took place between 1929 and 1933 is simply absurd, even though total factor productivity did fall. What happened was a failure of the exchange mechanism. This is something that no model, no matter how elaborate, of a long-lived Robinson Crusoe dealing with his changing world is going to confront. A model that embodies exchange is a minimum prerequisite for a serious theory of economic downturns.

The traditional Keynesian approach is to postulate that the exchange mechanism fails because prices are in some sense rigid, so they do not attain market-clearing levels and thereby frustrate exchange. This is far from being a satisfactory story. Most plausible reasons why prices might not change also imply that agents should not continue to act along static demand and supply curves. But it hardly follows that ignoring exchange failures because we do not yet fully understand them is a plausible strategy.

Where should one look for failures of the exchange process? Convincing evidence of the types of mechanisms that can lead to breakdowns of the exchange mechanism comes from analyses of breakdowns in credit markets. These seem to have played a crucial role in each of the postwar recessions. Indeed, while it is hard to account for postwar business cycle history by pointing to technological shocks, the account offered by, for example, Otto Eckstein and Allen Sinai (1986) of how each of the major recessions was caused by a credit crunch in an effort to control inflation seems compelling to me.

\section{Conclusion}

Even at this late date, economists are much better at analyzing the optimal response of a single economic agent to changing conditions than they are at analyzing the equilibria that will result when diverse agents interact. This unfortunate truth helps to explain why macroeconomics has found the task of controlling, predicting, or even explaining economic fluctuations so difficult. Improvement in the track record of macroeconomics will require the development of theories that can explain why exchange sometimes works well and other times breaks down. Nothing could be more counterproductive in this regard than a lengthy professional detour into the analysis of stochastic Robinson Crusoes. 


\section{References}

Altonji, Joseph G. 1982. The intertemporal substitution model of labour market fluctuations: An empirical analysis. Review of Economic Studies 49 (Special Issue): 783-824.

Barro, Robert J., and King, Robert G. 1982. Time-separable preferences and intertemporal-substitution models of business cycles. Working Paper 888. National Bureau of Economic Research.

Berndt, Ernst R. 1980. Energy price increases and the productivity slowdown in United States manufacturing. In The decline in productivity growth, pp. 60-89. Conference Series 22. Boston: Federal Reserve Bank of Boston.

Eckstein, Otto, and Sinai, Allen. 1986. The mechanisms of the business cycle in the postwar era. In The American business cycle: Continuity and change, ed. Robert J. Gordon, pp. 39-105. National Bureau of Economic Research Studies in Business Cycles, vol. 25. Chicago: University of Chicago Press.

Eichenbaum, Martin S.; Hansen, Lars P.; and Singleton, Kenneth J. 1986. A time series analysis of representative agent models of consumption and leisure choice under uncertainty. Working Paper 1981. National Bureau of Economic Research.

Fay, Jon A., and Medoff, James L. 1985. Labor and output over the business cycle: Some direct evidence. American Economic Review 75 (September): $638-55$.

Ghez, Gilbert R., and Becker, Gary S. 1975. The allocation of time and goods over the life cycle. New York: National Bureau of Economic Research.

Mankiw, N. Gregory; Rotemberg, Julio J.; and Summers, Lawrence H. 1985. Intertemporal substitution in macroeconomics. Quarterly Journal of Economics 100 (February): 225-51.

Mehra, Rajnish, and Prescott, Edward C. 1985. The equity premium: A puzzle. Journal of Monetary Economics 15 (March): 145-61. 